\title{
Learned Convention and Subgame Perfect Equilibrium in an Overlapping Generations Model with Two-Sided Altruism *
}

\author{
Professor Lakshmi K. Raut \\ California State University at Fullerton \\ Department of Economics \\ Fullerton, CA92834,USA
}

\begin{abstract}
This paper considers an overlapping generations model of endogenous fertility, savings and intergenerational transfers. While subgame perfect equilibrium notion is more relevent to analyze individual incentives in this set-up, due to computational complexity and lack of an appropriate equilibrium selection theory, most previous studies employed the open-loop Nash equilibrium. This paper introduces a unifying notion of equilibrium in which behaviors are guided by best responses, given a fixed convention and bounded rational expectations about other agents' behaviors. The paper provides an evolutionary process for convention based on learning. When the process converges, the limiting equilibrium is shown to be a subgame perfect equilibrium. This procedure provides a rationale for equilibrium selection and a method to compute subgame perfect equilibrium locally. Using this procedure, the paper studies the effect of a social security program on local subgame perfect equilibrium level of intergenerational transfers, fertility rate and welfare of a representative agent.
\end{abstract}

Keywords: Convention, Learning, Endogenous Fertility, Local Subgame Perfect Equilibrium.

\footnotetext{
${ }^{*}$ Correspondence: Professor Lakshmi K. Raut, Department of Economics, California State University at Fullerton, 800 N. St. College Blvd, LH-702, Fullerton, CA 92834. Phone: (714)278-5481. Fax: (714)2781548. E-mail: lraut@fullerton.edu
} 


\section{Learned Convention and Subgame Perfect Equilibrium in an Overlapping Generations Model with Two-Sided Altruism}

\section{Introduction}

There are many unresolved issues regarding the pay-as-you-go (PAYG) social security program and its effects on fertility, savings and intergenerational transfers in overlapping generations (OLG) economies. First, what should be an appropriate equilibrium concept to model individual incentives for intergenerational transfers? While the notion of subgame perfect equilibrium is an appropriate equilibrium concept, there are generally many equilibria and computation of a subgame perfect equilibrium in OLG set-up is very complex. This led most previous studies in this area to use the notion of open-loop Nash equilibrium which does not fully capture the incentives in the OLG framework. Second, the literature has remained elusive on the issues of why does there exist a PAYG social security program, and whether it can restore Pareto optimality or lead to a Pareto superior allocation for OLG economies.

Samuelson [1958] explained the need for a PAYG social security program to restore Pareto optimality in pure exchange OLG economies. He assumed that agents have lifecycle utility functions and thus there are no voluntary intergenerational transfers. Another type of explanation postulates that there could be economy of scale and other sources of market failures in pension provision (see, Diamond [1977]) or there might be adverse selection/moral hazard problems in private provision of retirement income insurance and these could be mitigated by compulsory participation (see Diamond and Mirrlees [1978]).

Veall [1986] provided an alternative explanation for PAYG social security. He considered an OLG model in which each agent is assumed to derive utility not only from his/her own life-cycle consumption, but also from the level of old-age consumption of his/her parents. Due to this consumption externality, elderly may save little to extract the maximum possible gifts from their children; "This can lead to an inferior steady state, where no one is consuming 'enough' in retirement" (Veall [1986, p.250). If a PAYG social security system is introduced such that it transfers from the young to the old at least the amount that the old could extract from their children by saving nothing, such a social security program could restore inter-temporal efficiency of consumption for each agent and Pareto optimality for 
the whole society. However, once the agents begin to save, the young may like to reduce their social security contribution and have incentive to amend the PAYG social security legislation. Thus such a PAYG system may not be stable. Veall showed that if social security benefits are set at the level of optimal steady-state old-age consumption, then such a legislation will be honored by all future generations and thus is stable. Moreover, the resulting allocation will be Pareto optimal.

Hansson and Stuart [1989] provided another closely related explanation by modeling PAYG social security legislation as a trade among living generations. They considered an OLG model in which agents derive utility not only from their own young age and old-age consumption but also from properly discounted young age and old-age consumption of their parents and of all future generations. They find conditions under which the young and the old agents would find it beneficial for them to agree upon a stream of PAYG social security transfers for the current and all future generations such that the resulting allocation is Pareto optimal and that no future generations would have incentives to amend the program.

These models did not endogenize fertility choices. If agents expect to receive gifts from their children to support old-age consumption, it is clear that not only savings decisions but also the fertility decisions will be affected; in fact, agents may like to have more children than what is socially optimal.[ Hence, it is important to relax the exogenous fertility assumption in the above class of models.

Recent models that study the effect of social security on fertility and savings (Barro and Becker [1989], and Raut [1990]) the existence of a social security is not explained. Nishimura and Zhang [1992] incorporated fertility choices in Veall's one-sided altruism framework. They used open-loop Nash equilibrium as a solution concept for decentralized economy and assumed that agents care only about their parent's old-age consumption but not about their children's well-being and then considered the possibility of implementing social optimal with social security in an open loop Nash equilibrium. Following Veall, they viewed the optimal old-age consumption in the steady-state as PAYG social security benefits. However, when fertility is also a choice variable, it is not possible to implement

\footnotetext{
${ }^{1}$ This is an alternative formulation of old-age security hypothesis. Raut and Tran [2004] studied theoretically and empirically an alternative formulation of old-age security motive. They examined how parental investment in children's human capital is affected when parents expect old-age transfers from their children. While human capital investment is an important intergenrational transfers decision, the focus of this paper is to study the link among the savings, fertility and old-age resource transfers decisions.
} 
the optimal steady-state allocation using only a PAYG social security policy instrument; this was possible in Veall's framework because he treated fertility as exogenous; in fact, once such a PAYG social security program is enacted, the free rider's problem would cripple the system since an individual agent will have no incentive to have children (as they do not affect utility but cost money). Parents would like to depend on others' children for contribution to social security program. Since every body would behave this way, such a social security program is not individually rational. Therefore, viewing optimal steadystate gifts as a form of PAYG social security in Veall's framework loses both normative and positive virtues once fertility is a choice variable.

In this paper, I extend the literature in two respects: First, I introduce two-sided paternalistic altruism of the type that agents derive utility not only from their own young age and old age consumption, but also from the old-age consumption of their parents and the young age consumption of their children. Second, I introduce a more general notion of equilibrium which includes open-loop Nash equilibrium and subgame perfect equilibrium notions as special cases. I assume that behaviors are guided by best responses, given a common fixed convention and bounded rational expectations about other agents' behaviors. I then provide a mechanism for agents in each generation to learn the common convention by observing their parent generation's behaviors. When the evolutionary process converges, I show that the limiting equilibrium produces a subgame perfect equilibrium. This procedure leads to both selection of a subgame perfect equilibrium and computation of an equilibrium locally. Using this procedure I study both analytically and numerically the effect of a social security program on local subgame perfect equilibrium rate of intergenerational transfer, fertility rate and welfare level of a representative agent.

In section 2, I set up the basic OLG model. In section 3, I define the notions of openloop Nash equilibrium, social optimum, and subgame perfect equilibrium. In section 4, I explain the bounded rational framework involving conventions, learning of conventions and the computation of a subgame perfect equilibrium locally. In section 5, I study properties of this equilibrium. Section 6 concludes the paper. 


\section{The Basic Framework}

I use the basic Samuelsonian [1958] overlapping generations framework and introduce twosided altruism to endogenize intergenerational transfers. Assume that time is discrete and is denoted as $t=0,1,2, \ldots$; each person lives for three periods: young, adult, and old. While young, he depends on his parents for all decisions. I follow the notational convention that a superscript $t$ refers to an adult of period $t$ and a subscript $t$ refers to time period $t$. For instance, $c_{t}^{t}$ and $c_{t+1}^{t}$ denote respectively the adult age and old-age consumption of an adult of period $\mathrm{t}$; however, $n_{t}$ denotes the number of children of an adult of period $t$, since I assume that only adults can have children, so from the subscript of $n_{t}$ we can identify which generation it corresponds to. Assume that for all $t \geq 1$, the wage rate $w_{t}$ and the interest rate $r_{t}$ are exogenously given.

Assume that all children are born identical and they all behave identically in a given situation. An agent's behavior regarding fertility, savings and intergenerational transfers are guided by concerns for the well-being of children and parents which I model by assuming that an adult of generation $t$ derives utility from his own life-cycle consumption and from consumption level of his children and parents that he observes during his active life-time (see Kohlberg [1976], and Pollak [1988] for use of similar utility functions in different contexts). More specifically, agent t's utility function is as follows:

$$
U^{t}=\delta\left(n_{t-1}\right) v\left(c_{t}^{t-1}\right)+\alpha v\left(c_{t}^{t}\right)+\beta v\left(c_{t+1}^{t}\right)+\gamma\left(n_{t}\right) v\left(c_{t+1}^{t+1}\right)
$$

Veall [1986] in his exogenous fertility framework and Nishimura and Zhang [1992] in their endogenous fertility framework assumed that $\gamma\left(n_{t}\right)=0$ and $\delta\left(n_{t}\right)$ to be constant, for all $t \geq 0$. In the above specification, I allow the degree of an individual's concern for his parents to depend on the number of siblings. However, most of our results hold if $\delta($.$) is$ constant. I will argue later that assuming $\gamma\left(n_{t}\right)=0$ leads to unsatisfactory modeling of fertility decisions.

An adult of period $t$ earns wage income $w_{t}$ in the labor market and expects to receive a bequest $b_{t}$ from his parents. These two sources of income constitute his budget during adulthood. Rearing cost per child in period $t$ is $\theta_{t}>0$ units of period $t$ good. Given his budget, he decides the amount of savings $s_{t}$, the number of children $n_{t} \geq 0$, the fraction of income to be transferred to his old parents $a_{t} \geq 0$; in the next period, he retires and 
expects to receive $a_{t+1} n_{t}$ amount of gifts from his children, earns $\left(1+r_{t+1}\right) s_{t}$ as return from his physical assets, and decides the amount of bequest $b_{t+1} \geq 0$ to leave for each of his children.

\begin{tabular}{||c|c|c|c|c|c|c|c||}
\hline \hline $\begin{array}{c}\text { time } \\
\text { generation }\end{array}$ & $t=1$ & $t=2$ & $t=3$ & $\cdots$ & $t-1$ & $t$ & $\cdots$ \\
\hline 0 & $b_{1}$ & & & & & & \\
\hline 1 & $\left(a_{1}, n_{1}, s_{1}\right)$ & $b_{2}$ & & & & & \\
\hline 2 & & $\left(a_{2}, n_{2}, s_{2}\right)$ & $b_{3}$ & $\cdots$ & & & \\
\hline$\ldots$ & & & & $\cdots$ & & & \\
\hline$t-1$ & & & & & $\left(a_{t-1}, n_{t-1}, s_{t-1}\right)$ & $b_{t}$ & \\
\hline$t$ & & & & & & $\left(a_{t}, n_{t}, s_{t}\right)$ & $\ldots$ \\
\hline$\ldots$ & & & & $\ldots$ & & & $\ldots$ \\
\hline \hline
\end{tabular}

Table 1: Time table of actions by overlapping generations of agents

The effects of agent $t$ 's action, $\alpha^{t}=\left(a_{t}, n_{t}, s_{t}, b_{t+1}\right)$, on the levels of his own life cycle consumption and the levels of consumption of his parents and children in the periods that overlap with his life-cycle, depend on his parent's action, $\alpha^{t-1}$ and his children's action $\alpha^{t+1}$ as follows:

$$
\begin{aligned}
c_{t}^{t}+s_{t}+\theta_{t} n_{t}= & \left(1-a_{t}\right) w_{t}+b_{t} \\
c_{t+1}^{t}+n_{t} b_{t+1}= & \left(1+r_{t+1}\right) s_{t}+a_{t+1} w_{t+1} n_{t} \\
c_{t}^{t-1}= & \left(1+r_{t}\right) s_{t-1}-n_{t-1} b_{t}+a_{t} w_{t} n_{t-1} \\
c_{t+1}^{t+1}= & \left(1-a_{t+1}\right) w_{t+1}+b_{t+1}-s_{t+1}-\theta_{t+1} n_{t+1} \\
& c_{t}^{t}, c_{t+1}^{t} \geq 0
\end{aligned}
$$

Similarly, the agent $t=0$ 's utility function is given by

$$
W_{0}=\beta v\left(c_{1}^{0}\right)+\gamma\left(n_{0}\right) v\left(c_{1}^{1}\right)
$$

and agent $t=0$ decides the level of bequest $b_{1}$, given his past decisions, $n_{0}, s_{0}$, and his children's decisions, $\alpha^{1}$. The arguments of his utility function are given by

$$
\begin{aligned}
c_{1}^{0}+n_{0} b_{1}= & \left(1+r_{1}\right) s_{0}+a_{1} w_{1} n_{0} \\
c_{1}^{1}= & \left(1-a_{1}\right) w_{1}+b_{1}-s_{1}-\theta_{1} n_{1} \\
& c_{1}^{0} \geq 0
\end{aligned}
$$




\section{Equilibrium notions}

\subsection{Open-loop Nash Equilibrium}

Note that if $1>a_{t}^{*}>0$ and $b_{t}^{*}>0$ is an equilibrium combination of gifts and bequest in period t, so is $a_{t}^{*}+\epsilon$ and $b_{t}^{*}+\epsilon w_{t}$, for small $\epsilon>0$; this can lead to gift-bequest war. This could be handled by requiring an equilibrium to yield either positive bequest or positive gift within a period but not both. Most commonly used equilibrium concept is an open-loop Nash equilibrium which I define as follows:

A sequence of strategies, $\left\{\alpha^{t}\right\}_{t=0}^{\infty}$ is feasible if there exists an associated sequence of non-negative consumption stream $c_{1}^{0},\left\{c_{t}^{t}, c_{t+1}^{t}\right\}_{1}^{\infty}$ such that it satisfies the budget constraints (27)-(7).

Definition 1 An open loop Nash equilibrium is a sequence of feasible strategies $\left\{\alpha^{t}\right\}_{0}^{\infty}$ such that for given initial condition, $n_{0}, s_{0}$

(i) $a_{t}>0 \Rightarrow b_{t}=0$ and $b_{t}>0 \Rightarrow a_{t}=0$

(ii) for any $t \geq 1$, given $\alpha^{t-1}=\left(a_{t-1}, n_{t-1}, s_{t-1}, b_{t}\right)$ and $\alpha^{t+1}=\left(a_{t+1}, n_{t+1}, s_{t+1}, b_{t+2}\right)$ there does not exist another strategy $\tilde{\alpha}^{t}$ for agent $t$ such that $\tilde{\alpha}^{t}$ together with $\alpha^{\tau}, \tau \neq$ $t, \tau \geq 0$ form a feasible sequence of strategies, and $\tilde{\alpha}^{t}$ yields higher utility for agent $t$.

I distinguish further among different types of equilibria. An open-loop bequest equilibrium is an equilibrium of the above type that satisfies $a_{t}=0$, and $b_{t}>0$ for all $t \geq 1$. An open-loop gift equilibrium is an equilibrium of the above type that further satisfies $b_{t}=0$, and $a_{t}>0$ for all $t \geq 1$.

\subsection{Social Optimum}

Following Samuelson [1958], I define a social optimum to be an allocation of consumption $\left(c_{y}, c_{o}\right)$ between adults and olds within a given generation and the number of children $n$ such that a representative agent's utility in a stationary economy is maximized. More formally, the problem is to choose $c_{y}, c_{0}$, and $n$ 


$$
\begin{aligned}
& \max (\alpha+\gamma(n)) v\left(c_{y}\right)+(\beta+\delta(n)) v\left(c_{o}\right) \\
& \text { subject to } \\
& c_{y}+\frac{c_{0}}{1+n}=w-n \theta
\end{aligned}
$$

I use this in the numerical example section.

\subsection{Subgame Perfect Equilibrium}

An open loop Nash equilibrium framework does not fully model the incentives that agents may have to manipulate their parents' or their children's behavior to extract more transfers from them. For instance, since parents make their consumption and fertility decisions prior to their children's, parents may find it strategically advantageous to consume more in their working age, save little on physical assets and possibly have more children so that when they become old they have little income of their own. When the children find that their old parents have little to consume, they will have sympathy for their parents since they care about their parents' consumption; thus they will transfer a larger amount of old-age support than what they would be transferring in the open loop Nash equilibrium. The children in turn can manipulate their children in the same way and the process could go on for ever.

To proceed more formally, I assume a particular sequencing of decisions within each period in order to compute and study the properties of subgame perfect equilibrium. More specifically, I divide each time period $t$ into two stages denoted by $t$ and $t .1$ (stage $t .1$ follows stage $t$ ) at which the live agents of period t are to make decisions. At stage $t$, which is the beginning of period $t$, the agent $t-1$ 's decisions $\left(a_{t-1}, n_{t-1}, s_{t-1}\right)$ are part of history and are assumed to be observable to the live agents $t-1$ and $t$. Denote these past decisions at stage $t$ by $h_{t}$. Given a realization of the history $h_{t}$, the agent $t-1$ decides to bequeath $b_{t}$ to each of his children and each of his children decides the fraction $a_{t}$ of their income to be given as gift to their parents. Both agents make their decisions simultaneously and independently. The game moves to stage $t .1$ at which both agents observe the outcome up to stage $t .1$. Denote a typical realization of these decisions at stage $t .1$ by $h_{t .1}$. Given a realization of the history $h_{t .1}$ at stage $t .1$, the agent $t-1$ does not make anymore household decision, agent $t$, however, decides the number of children and savings $\left(n_{t}, s_{t}\right)$. Figure 1 depicts a part of the extensive form of the game starting at stage $t$. The tree is shown only 
up to stage $t+1.1$; the label of a branch describes the action of the agent that it corresponds to; the shaded boxes are the information sets of the agents within a given stage.

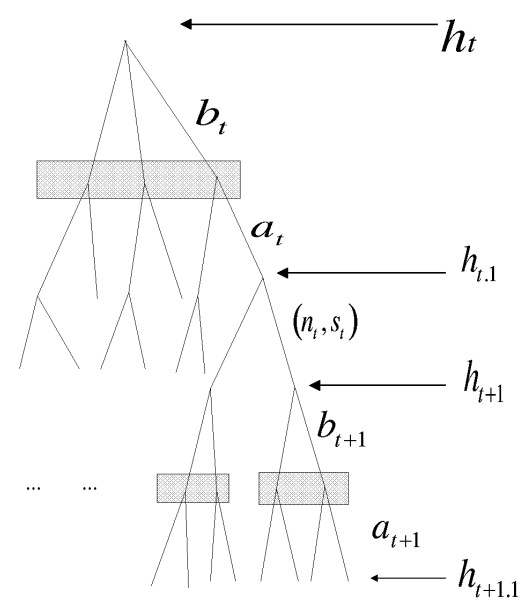

Figure 1: Extensive form representation of the multi-stage game, $\Gamma\left(h_{t}\right)$

Since at stage $t$ the parent $t-1$ knows that his children will use the information regarding his observable actions, he will choose his actions in a manner that exploits the reactions of his children in most favorable way. Or in other words, parents may find it beneficial to manipulate their children's behavior. In the above set-up, agents in later stages can use very complex punishment rules as their strategies. For instance, an agent $t=5$ in stage 5 can condition his actions as follows:

"he will transfer a certain fraction $a_{5}$ of his income to his parents if his parents transferred a certain fraction $a_{4}$ of their income to the agent's grandparents, saved certain amount $s_{4}$, had certain number of children, $n_{4}$, and if his grand parents transferred a certain fraction $a_{3}$ of their income to the agent's grand grand parents, ... and so on."

While these types of strategies may lead to many subgame perfect equilibria, the equilibria that prescribe strategies conditioning on the dead grand parents are hard to execute since it is not possible to objectively verify if the agent's grand parents or grand grand par- 
ents did such and such. I consider only pay-off relevant strategies: From equations (2)-(5), and the arguments of the utility function, it is clear that the only information from history that is relevant to decision making of the agents at stage $t$ is agent $t-1$ 's own past decision regarding $\left(s_{t-1}, n_{t-1}\right)$, and thus I consider the bequest decision rule of agent $t-1$ to be of the form $b_{t}\left(n_{t-1}, s_{t-1}\right)$, and the old-age transfer decision rule of agent $t$ to be of the form $a_{t}\left(n_{t-1}, s_{t-1}\right)$; similarly at stage $t .1$, the agent $t$ 's actions depend on his own past decision $a_{t}$ and his parent's bequest decision $b_{t}$, only through the net effect, $a_{t} w_{t}-b_{t}$ which I represent as functions of the form, $n_{t}=n_{t}\left(a_{t} w_{t}-b_{t}\right)$, and $s_{t}=s_{t}\left(a_{t} w_{t}-b_{t}\right)$. Thus agent $t$ 's strategies are functions of the type: $a_{t}=a_{t}\left(n_{t-1}, s_{t-1}\right), n_{t}=n_{t}\left(a_{t} w_{t}-b_{t}\right)$, and $s_{t}=s_{t}\left(a_{t} w_{t}-b_{t}\right)$ and $b_{t+1}\left(n_{t}, s_{t}\right)$. Whenever actions at any stage are functions of past actions, they are known as reaction functions. Putting all the actions and reactions of agent $t$ from all stages of the game together, it is easy to see that a profile of pure strategies of all agents together is given by,

$\mathcal{A}_{t}=\left\{\begin{array}{lc}\left(a_{t}\left(n_{t-1}, s_{t-1}\right), n_{t}\left(a_{t} w_{t}-b_{t}\right), s_{t}\left(a_{t} w_{t}-b_{t}\right), b_{t+1}\left(n_{t}, s_{t}\right)\right) & \text { for all agents } t \geq 1 \\ b_{1}\left(n_{0}, s_{0}\right) & \text { for agent } t=0\end{array}\right.$

where, each component belongs to the relevant strategy space specified above. Note that agent $t$ 's actions, $n_{t}, s_{t}, a_{t}$, and $b_{t+1}$ now belong to function spaces, whereas in open loop Nash equilibrium they were non-negative real numbers. I use the following characterization of the subgame perfect equilibrium notion.

Definition 2 Let $n_{0}$ and $s_{0}$ be the initial condition. A profile of strategies, $\mathcal{A}_{t}^{*}=$ $\left(a_{t}^{*}\left(n_{t-1}, s_{t-1}\right), n_{t}^{*}\left(a_{t} w_{t}-b_{t}\right), s_{t}^{*}\left(a_{t} w_{t}-b_{t}\right), b_{t+1}^{*}\left(n_{t}, s_{t}\right)\right)$, for agent $t \geq 1$, and $\mathcal{A}_{0}^{*}=$ $b_{1}^{*}\left(n_{0}, s_{0}\right)$ for agent $t=0$, is said to be a subgame perfect equilibrium if

1. for all agents $t \geq 1$ and for any $n_{t-1}, s_{t-1}, b_{t}=b_{t}^{*}\left(n_{t-1}, s_{t-1}\right)$, given $a_{t+1}^{*}(.,$.$) ,$ $n_{t+1}^{*}(),. s_{t+1}^{*}($.$) the strategies a_{t}=a_{t}^{*}\left(n_{t-1}, s_{t-1}\right), n_{t}=n_{t}^{*}\left(a_{t} w_{t}-b_{t}\right), s_{t}=s_{t}^{*}\left(a_{t} w_{t}-\right.$ $\left.b_{t}\right), b_{t+1}=b_{t+1}^{*}\left(n_{t}, s_{t}\right)$ maximize $U_{t}$, subject to agent t's budget constraint determined by the given optimal reaction functions of the other agents, and

2. for agent $t=0$, given $\left(n_{0}, s_{0}\right)$, and the optimal reaction functions $a_{1}^{*}(.,),. n_{1}^{*}(),. s_{1}^{*}($. of agent $t=1$, the reaction function $b_{1}^{*}\left(n_{0}, s_{0}\right)$ maximizes his utility within his budget constraint determined by the given optimal reaction functions of agent 1 . 


\subsubsection{The First Order Conditions for a Subgame Perfect Gift Equilibrium}

Let $a_{t+1}\left(n_{t}, s_{t}\right), n_{t+1}\left(a_{t+1} w_{t+1}-b_{t+1}\right), s_{t+1}\left(a_{t+1} w_{t+1}-b_{t+1}\right)$ be the optimal reaction functions of agent $t+1$, and let $n_{t-1}, s_{t-1}$ be any feasible actions of agent $t-1$. Taking these decisions as given, agent $\mathrm{t}$ chooses a feasible $\mathcal{A}_{t}=a_{t}\left(n_{t-1}, s_{t-1}\right), n_{t}\left(a_{t} w_{t}-b_{t}\right)$, $s_{t}\left(a_{t} w_{t}-b_{t}\right), b_{t+1}\left(n_{t}, s_{t}\right)$ that maximizes his utility. For $t>1$, the first order necessary conditions for his maximization problem are as follows:

\section{At stage t:}

$$
\begin{gathered}
\delta\left(n_{t-1}\right) n_{t-1} \mathbf{v}^{\prime}(\overbrace{\left(1+r_{t}\right) s_{t-1}+a_{t} w_{t} n_{t-1}-n_{t-1} b_{t}}^{c_{t}^{t-1}}) \ldots \\
-\alpha \mathbf{v}^{\prime}(\overbrace{\left(1-a_{t}\right) w_{t}-s_{t}-\theta_{t} n_{t}+b_{t}}^{c_{t}^{t}}) \leq 0, \text { and }=0 \text { if } a_{t}>0 \\
-\beta \mathbf{v}^{\prime}\left(c_{t}^{t-1}\right) n_{t-1}+\gamma\left(n_{t-1}\right) \mathbf{v}^{\prime}\left(c_{t}^{t}\right)\left[1-\theta_{t} n_{t}^{\prime}\left(b_{t}-a_{t} w_{t}\right)-s_{t}^{\prime}\left(b_{t}-a_{t} w_{t}\right)\right] \leq 0, \\
\text { and }=0 \text { if } b_{t}>0
\end{gathered}
$$

\section{At stage t.1:}

$$
\begin{gathered}
\left.-\alpha \mathbf{v}^{\prime}\left(c_{t}^{t}\right)+\beta \mathrm{v}^{\prime}(\overbrace{\left[1+r_{t+1}\right) s_{t}+a_{t+1}(.) w_{t+1} n_{t}-n_{t} b_{t+1}}^{c_{t+1}^{t+1}}]\right) \times \\
\left[\left(1+r_{t+1}\right)+w_{t+1} n_{t} a_{t+1,2}\left(n_{t}, s_{t}\right)\right]-\gamma\left(n_{t}\right) \mathrm{v}^{\prime} \overbrace{(\overbrace{t+1,2}\left(n_{t}, s_{t}\right) w_{t+1}] \leq 0, \text { and }=0 \text { if } s_{t}>0}^{\left.c_{t+1}\right) w_{t+1}-s_{t+1}-\theta_{t+1} n_{t+1}+b_{t+1}}) \times \\
-\alpha \theta \mathbf{v}^{\prime}\left(c_{t}^{t}\right)+\beta \mathbf{v}^{\prime}\left(c_{t+1}^{t}\right)\left[a_{t+1}\left(n_{t}, s_{t}\right) w_{t+1}+n_{t} w_{t+1} a_{t+1,1}\left(n_{t}, s_{t}\right)\right] \ldots \\
+\gamma^{\prime}\left(n_{t}\right) \mathrm{v}\left(c_{t+1}^{t+1}\right)-\gamma\left(n_{t}\right) \mathbf{v}^{\prime}\left(c_{t+1}^{t+1}\right)\left[w_{t+1} a_{t+1,1}\left(n_{t}, s_{t}\right)\right] \leq 0, \text { and }=0 \text { if } n_{t}>0
\end{gathered}
$$

Similar to open loop Nash equilibrium, I can define subgame perfect gift equilibrium and subgame perfect bequest equilibrium. However, in the rest of the paper I analyze only the properties of the subgame perfect gift equilibria.

In this framework, a subgame perfect equilibrium with differentiable reaction functions may not exist. Even when there exists one, it is not possible to compute all subgame perfect 
gift equilibrium reaction functions from the above first order conditions. 2] If we further restrict to a stationary local subgame perfect equilibrium, could we compute it using the first order conditions? More formally, assume that the wage rate $w_{t}=w$, the interest rate $r_{t}=r$, and the cost of raising children $\theta_{t}=\theta$ for all $t \geq 1$.

Definition 3 A stationary local subgame perfect gift equilibrium is a vector of fertility level, savings amount, and the rate of old-age support to parents, $\left(n^{*}, s^{*}, a^{*}\right) \geq 0$ and a vector of reaction functions $\left(a\left(n_{t-1}, s_{t-1}\right), n\left(a_{t} w_{t}-b_{t}\right), s\left(a_{t} w_{t}-b_{t}\right)\right)$ defined in a neighborhood ${ }^{\beta}$ of $\left(n^{*}, s^{*}, a^{*}\right)$ such that

$$
\left.a^{*}=a\left(n^{*}, s^{*}\right), n^{*}=n\left(a^{*} w\right)\right), s^{*}=s\left(a^{*} w\right)
$$

and

$$
\begin{array}{r}
a_{t}\left(n_{t-1}, s_{t-1}\right)=a\left(n_{t-1}, s_{t-1}\right) \\
n_{t}\left(a_{t} w_{t}-b_{t}\right)=n\left(a_{t} w_{t}-b_{t}\right) \\
s_{t}\left(a_{t} w_{t}-b_{t}\right)=s\left(a_{t} w_{t}-b_{t}\right) \\
b_{t}\left(n_{t-1}, s_{t-1}\right)=0 \text { for all } t \geq 1
\end{array}
$$

and that the above satisfies the system of equations (8)-(II) for all $t \geq 1$ with initial condition, $n_{0}=n^{*}$, and $s_{0}=s^{*}$.

Could one compute a stationary local subgame perfect equilibrium reaction functions from the above first order conditions (8)-(11) ? To that end, denote the one period lag value and the one period forward value of a variable $x$ by $x_{-}$and $x^{+}$respectively, the system of equations $(8)-(11)$ for a stationary subgame perfect equilibrium becomes:

$$
\begin{gathered}
\Psi^{a}\left(a\left(n_{-}, s_{-}\right), s+\theta n\right) \equiv \frac{\delta\left(n_{-}\right) n_{-}}{\alpha}=\frac{\left.\mathrm{v}^{\prime}([1-a(.)] w-s-\theta n)\right)}{\mathrm{v}^{\prime}\left((1+r) s_{-}+a(.) w n_{-}\right)} \\
\Psi^{b}\left(a\left(n_{-}, s_{-}\right), s+\theta n\right) \equiv-\beta \mathrm{v}^{\prime}\left((1+r) s_{-}+a(.) w n_{-}\right) n_{-}+\gamma\left(n_{-}\right) \ldots \\
\left.\mathrm{v}^{\prime}([1-a(.)] w-s-\theta n)\right)\left[1-\theta n^{\prime}-s^{\prime}\right] \leq 0 \text { and }=0 \text { if } b>0
\end{gathered}
$$

\footnotetext{
${ }^{2}$ See Kohlberg [1976] for a discussion of such problems in a similar framework.

${ }^{3}$ The adjective "local" in the definition refers to this neighborhood restriction.
} 


$$
\begin{gathered}
\Psi^{s}\left(a\left(n_{-}, s_{-}\right), a^{+}(n, s), a_{2}^{+}(n, s), n, s, s^{+}+\theta n^{+}\right) \equiv \\
\left.-\alpha \mathrm{v}^{\prime}([1-a] w-s-\theta n)\right)+\beta \mathrm{v}^{\prime}((1+r) s+a(n, s) n w)\left((1+r)+n w a_{2}(n, s)\right) \ldots \\
-\gamma(n) \mathrm{v}^{\prime}\left([1-a(n, s)] w-s^{+}-\theta n^{+}\right)\left[a_{2}^{+}(n, s) w\right] \leq 0 \text { and }=0 \text { if } s>0 \\
\Psi^{n}\left(a\left(n_{-}, s_{-}\right), a^{+}(n, s), a_{1}^{+}(n, s), n, s, s^{+}+\theta n^{+}\right) \equiv \\
\left.-\alpha \theta \mathrm{v}^{\prime}([1-a] w-s-\theta n)\right)+\beta \mathrm{v}^{\prime}\left((1+r)+w n a^{+}(n, s)\right) \times \\
{\left[a^{+}(n, s) w+a_{1}^{+}(n, s) w n\right]+\gamma^{\prime}(n) \mathrm{v}\left(\left[1-a^{+}(n, s)\right] w-s^{+}-\theta n^{+}\right) \ldots} \\
-\gamma(n) \mathrm{v}^{\prime}\left(\left[1-a^{+}(n, s)\right] w-s^{+}-\theta n^{+}\right)\left[a_{1}^{+}(n, s) w\right] \leq 0, \text { and }=0 \text { if } n>0
\end{gathered}
$$

Since we are trying to compute a local gift equilibrium, we restrict our computation to a neighborhood in which $b\left(n_{-}, s_{-}\right) \equiv 0$, and thus assume that the no bequest constraint in equation (13) is satisfied as an inequality. Notice that one can solve for $a($.$) as a function$ of $n_{-}$and $s_{-}$from equation (12) treating $n$ and $s$ as given, and then solve for $n$ and $s$ from equations (14)-(15) after plugging in the values of $a(),. a_{1}($.$) and a_{2}($.$) . This cannot work$ since $n$ and $s$ in equation (12) are implicit functions of $a$, and hence it will not be possible to calculate $a(),. a_{1}($.$) and a_{2}($.$) from equation (12) alone. This is a curse on subgame perfect$ equilibrium in overlapping generations models.

\section{Convention, Learning, and Subgame Perfect Gift Equilibrium}

In the previous section we saw that it was not possible to compute a subgame perfect gift equilibrium even locally around a steady-state using the first order conditions. Furthermore, there are generally multiple subgame perfect equilibria, and the literature on equilibrium selection theory does not guide us in the overlapping generations context to select an equilibrium. To make progress, I adopt the recent developments in evolutionary game theory for repeated normal form finite games to the OLG set-up.

Much of the evolutionary game theory literature assumes that a game with a finite number of pure strategies is played repeatedly many times by randomly drawn players from a large population (see for instance Fudenberg and Levine [1998], and Weibull[1995]). It 
combines two processes: a selection process that postulates which strategies yield higher pay-offs given the actions of all players, and a mutation process which randomly creates exceptions to the evolutionary process. The selection process has been formulated in various ways. For instance, as natural selection, imitation reinforcement and best response. In this paper, I consider a best response model with bounded rational expectations about other agents' behaviors and define a notion of equilibrium with fixed common convention that encompasses open-loop Nash equilibrium and subgame perfect equilibrium as specializations of this equilibrium.

\subsection{Gift Equilibrium with a common convention}

The bounded rationality of this paper consists of three assumptions: First, at every stage $t$, each agent follows a common "convention" that if he transfers a fraction $a_{t}$ of his income to his old-parents at stage $t$, then he spends $S_{t}=\sigma\left(a_{t}\right)$ on savings for old-age and on children at stage $t .1$. Here $\sigma($.$) is a convention. It is common to all individuals. It could be$ viewed as a threat strategy that a child may use if his parent did not save enough for old-age. Second, each agent assumes that his children will react to his decisions exactly the way he reacts to his parent's decisions, that is the reaction function $a()$ that he chooses will be also the reaction function of his children. Third, given a convention $\sigma()$, an individual chooses an action that maximizes his utility, i.e., individual behavior is guided by best response given a convention $\sigma()$ and assumption about others' behaviors.

Assuming that the conventions belong to a well-behaved family of functions, notice that given a decision $\left(a_{-}, n_{-}, s_{-}\right)$of the parent generation, (using implicit function theorem) one can solve for the best response $\left(a\left(n_{-}, s_{-}\right), n(a), s(a)\right)$ from equations (12), (13) and (15) as follows: The reaction function $a($.$) is a solution of equation (12) with$ $s+\theta n=\sigma\left(a\left(n_{-}, s_{-}\right)\right) ;$the other two functions $n(a), s(a)$ are solutions of equations (14) and (15) after substituting $s^{+}+\theta n^{+}=\sigma(a(n, s))$. I denote the set of best responses by $B R\left(a_{-}, n_{-}, s_{-} ; \sigma\right)$ whose elements are the vectors $(a, n, s)$ of optimal choices of adult agent $t$. While in general $B R\left(a_{-}, n_{-}, s_{-} ; \sigma\right)$ could be a correspondence, I assume that economies satisfy conditions such that $B R\left(a_{-}, n_{-}, s_{-} ; \sigma\right)$ is a function. Given a population distribution $\mu_{-}$of decisions $\left(a_{-}, n_{-}, s_{-}\right)$by adults of previous generation, and given a convention $\sigma$, the best response function $B R\left(a_{-}, n_{-}, s_{-} ; \sigma\right)$ determine the distribution of $\mu$ 
of current generation's decisions $(a, n, s)$ and the reaction functions $\left(a\left(n_{-}, s_{-}\right), n(a), s(a)\right)$. For a given $\sigma$, I refer to $B R\left(a_{-}, n_{-}, s_{-} ; \sigma\right)$ as a stationary gift equilibrium with common convention $\sigma$.

The above bounded rationality is very strong and not self-fulfilling. To see this, assume that a convention $\sigma()$ is followed at stage $t .1$. Parents make their bequest decision $b_{t}=0$ and an adult child make his old-age transfer decision $a_{t}$ at stage $t$ that maximize their respective utility functions. But when the game moves to stage $t .1$, the children choose their best responses $n_{t}\left(a_{t}\right)$ and $s_{t}\left(a_{t}\right)$ given $a_{t}$ which may not satisfy the convention that was assumed at stage $t$, i.e., $\bar{\sigma}(a) \equiv \theta n_{t}(a)+s_{t}(a)$ may not be equal to $\sigma(a)$ that was assumed at stage $t$, i.e. his decisions are not time-consistent. I will address this in the subsection on learning. The following result is now straightforward.

Proposition 1 Suppose $\left(a\left(n_{-}, s_{-}\right), n, s\right) \in B R\left(a_{-}, n_{-}, s_{-} ; \sigma^{*}\right)$ is a stationary gift equilibrium with a fixed convention $\sigma^{*}$ such that $s(a)+\theta n(a)=\sigma^{*}(a)$. Then $a\left(n_{-}, s_{-}\right), n(a), s(a)$ is a stationary subgame perfect gift equilibrium.

Notice that the fixed convention $\sigma($.$) corresponding to a subgame perfect equilibrium$ does not have the time inconsistency problem mentioned above. But how do individuals in a society arrive at such a common convention? I address this in the next subsection.

\subsection{The Gift Equilibrium with Learned Conventions}

In the previous subsection I assumed that individuals somehow know the subgame perfect convention $\sigma(a)$. In this section I provide a learning mechanism starting with an arbitrary convention and an evolutionary process with and without mutation, and show that when the learning process converges, the limiting distribution gives a subgame perfect equilibrium. This learning procedure could also be used to compute a subgame perfect equilibrium.

\subsubsection{Learning}

Let $\mu_{t-1}$ be the population distribution of actions $\left(a_{t-1}, n_{t-1}, s_{t-1}\right)$ that are chosen by the adults of generation $t-1$. The old parents and the adult children at stage $t$ observe the distribution $\mu_{t-1}$, and then compute conditional expectation of $S_{t-1} \equiv \theta n_{t-1}+s_{t-1}$ given $a_{t-1}$. Let this conditional expectation be denoted as $\sigma_{t-1}\left(a_{t-1}\right)$. At stage $t$, old parents and 
their adult children presume this will be the convention that will be followed in future and make choices $\left(a_{t}, n_{t}, s_{t}\right) \in B R\left(a_{t-1}, n_{t-1}, s_{t-1} ; \sigma_{t-1}\right)$. Note that given the distribution $\mu_{t-1}$ of $\left(a_{t-1}, n_{t-1}, s_{t-1}\right)$, the associated convention $\sigma_{t-1}$, and the best response function $B R\left(a_{t-1}, n_{t-1}, s_{t-1} ; \sigma_{t-1}\right)$, the distribution $\mu_{t}$ of actions $\left(a_{t}, n_{t}, s_{t}\right)$ and the convention $\sigma_{t}$ (which is the conditional expectation of $S_{t} \equiv \theta n_{t}+s_{t}$ given $a_{t}$ ) are determined and the process iterates over time to go on for ever. Denote the evolutionary process for convention by $\sigma_{t}=\Phi\left(\sigma_{t-1}\right)$. When this process converges, it converges to a fixed point $\sigma^{*}$ of this map $\Phi$, which is the long-run learned convention, and it is self-fulfilling and time consistent and hence also a subgame perfect equilibrium.

It is possible that when the process $\sigma_{t}=\Phi\left(\sigma_{t-1}\right)$ converges to the fixed point $\sigma^{*}$, the support of the distribution $\mu_{t}$ might shrink to the degenerate distribution concentrated at a point $\left(a^{*}, n^{*}, s^{*}\right) \in B R\left(a^{*}, n^{*}, s^{*} ; \sigma^{*}\right)$. Then there will be no variation in the population distribution of optimal actions. How does one learn the reaction functions if there is only one type of observation? In evolutionary game theory the problem is handled by assuming that, in each period, a fraction $\varepsilon$ of population experiments or mutates i.e., instead of choosing $\left(a_{t}, n_{t}, s_{t}\right) \in B R\left(a_{t-1}, n_{t-1}, s_{t-1} ; \sigma_{t-1}\right)$, an agent makes a random choice around $\left(a_{t}, n_{t}, s_{t}\right)$ in their feasible set. This creates varieties and the support of the distribution $\mu_{t}$ does not degenerate. One then studies the limiting invariant distribution $\mu^{*}$ and learned convention $\sigma^{*}$. I pursue this line of enquiry in another paper.

\subsection{Computation of local gift equilibria with learned conventions}

I now use the learning algorithm to compute a local subgame perfect equilibrium and study the effect on the equilibrium when a PAYG social security program is introduced. Notice that since we are computing a local subgame perfect equilibrium, we can restrict our computation to a small neighborhood around a steady-state $\left(a^{*}, n^{*}, s^{*}\right)$ and to a linear specification for $\sigma($.$) of the following form:$

$$
\sigma(a)=s^{*}+\theta n^{*}+\left(a-a^{*}\right) w \sigma^{\prime}
$$

Assume that the utility function satisfies the following: 


\section{Assumption A: 1 (constant elasticity of marginal utility (CEM) function)}

$$
v(c)=\frac{c^{1-\rho}}{1-\rho}, \rho \neq 1,0<\rho<\infty
$$

where $-\rho$ measures the elasticity of marginal utility.

Assumption A: $2 \gamma(n)=\gamma_{0} n^{1-\gamma_{1}}, 0 \leq \gamma_{1}<1$

The significance of this assumption is that parents care about consumption of all children equally. However, the weight they give to such consumption decreases with the number of children whenever $\gamma_{1}>0$.

Assumption A: $3 \delta(n)=\delta_{0} n^{\delta_{1}-1}, 0 \leq \delta_{1} \leq 1$

I refer this economy as CEM economy. Consider a PAYG social program of the type that the an adult of generation $t$ pays $\tau w_{t}$ as social security taxes, and receives $\tau n_{t} w_{t+1}$ as social security benefits when he is old. Although, the benefits $\tau n_{t} w_{t+1}$ depends on agent $t$ 's number of children $n_{t}$, he takes it as an externality. For a given value of $\sigma^{\prime}=\sigma^{\prime *}$ the steady-state local learning equilibrium $a(n, s)$ for our CEM economy is given by

$$
a(n, s)=\frac{\left(\delta_{0} / \alpha\right)^{1 / \rho} n^{\delta_{1} / \rho}\left(w-\tau w-\left[s^{*}+\theta n^{*}-a^{*} \sigma^{\prime *}\right]\right)-(1+r) s-n \tau w}{w\left(n+\left(1+\frac{\sigma^{\prime *}}{w}\right)\left(\delta_{0} / \alpha\right)^{1 / \rho} n^{\delta_{1} / \rho}\right)}
$$

For all reasonable non-negative values of $\sigma^{\prime *}$, it is clear from equation $(18)$ that $\frac{\partial a}{\partial \tau}<0$, and it is not necessarily equal to -1 . That is social security does not perfectly crowdout private transfers. One can easily verify that both $a_{1}($.$) and a_{2}($.$) are negative for this$ reaction function. While it is not possible to analytically derive the effect of $\tau$ on fertility and savings, for various values of $\sigma^{\prime}$, I numerically found the effect of $\tau$ on equilibrium fertility level to be always negative.

A typical phase diagram for the evolution of convention that emerged in our numerical CEM economies is shown in figure \&. From the figure, it is clear that there are two local subgame perfect gift equilibria, and the learning convention converges to the stable equilibrium. 


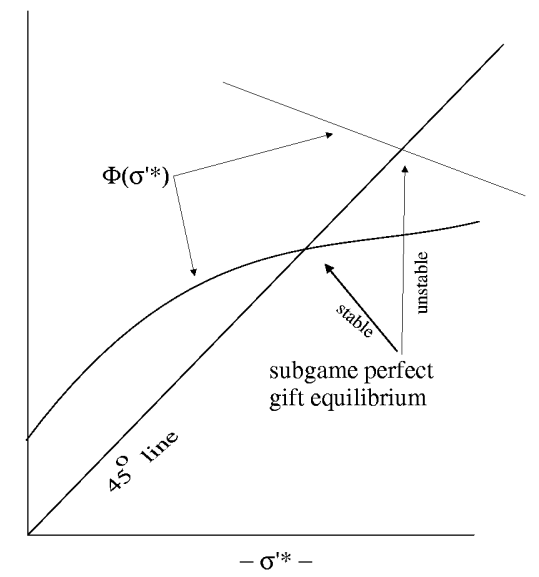

Figure 2: Phase diagram of Learning dynamics

I assume that $\delta_{1}=.8 ; \gamma_{0}=.3, \gamma_{1}=.6 ; \rho=1.5 ; \alpha=.4 ; \beta=.34 ; r=.05$; $w=10$; and $\theta=.1$. For $\delta_{0}$, I consider two cases: (1) $\delta_{0}=0.35$ and (2) $\delta_{0}=0.01$. The main difference between the two cases is that in the first case agents are assumed to care relatively heavily for their parents as compared to the second case. This will have implication for social security as we will see shortly. For various values of $\sigma^{\prime *}$, I numerically solved steady-state gift equilibrium using MathSoft's Maple software and using my own $\mathrm{C}++$ programs. The numerical strategy I used is as follows: I chose an initial value $\sigma_{0}^{\prime *}$ close to the fixed point and simulated the learning equilibrium path $\left\{\sigma_{t}^{\prime *}\right\}_{t \geq 1}$. I found that in the case of $s=0,\left\{\sigma_{t}^{\prime *}\right\}_{t \geq 1}$ converged to a stable local subgame perfect gift equilibrium, $\sigma_{s}^{\prime *}=-0.121472602158$ (the equilibrium allocation is shown in table 2 in the row with $\tau=0$ and Equilibrium Concept $=$ Learned convention). For the equilibrium type with $s>0$, none of the sequences of learning equilibria that I considered converged. The same phenomenon is true for the economy with social security tax rate $\tau=.035$. The equilibria corresponding to second set of parameter values are presented in table 3 .

For all the values of $\sigma^{\prime *}$ that I considered, I found two equilibria one with $s=0$ and the 
other one with $s>0$, and the former equilibrium always produced a higher level of utility and a higher level of old-age support in the steady-state. Furthermore, a gift equilibrium with fixed convention with respect to a large $\sigma^{\prime *}$ is very close to the corresponding openloop Nash equilibrium. In panels (a) and (b) of figure 3 corresponding to the cases $s=0$ and $s>0$, I have plotted the graph of $\Phi\left(\sigma^{*}\right)$ around its fixed points for our calibrated economy.

Table 2: Steady-state local learning and subgame perfect gift equilibria for the economy with $\delta_{0}=0.35$

\begin{tabular}{|c|l|c|c||}
\hline \hline$\tau$ & $\begin{array}{l}\text { Equilibrium } \\
\text { Concept }\end{array}$ & $\sigma^{*}$ & $\left(n^{*}, s^{*}, a^{*}, U_{\max }\right)$ \\
\hline 0 & $\begin{array}{l}\text { Nash } \\
\text { Equilibrium }\end{array}$ & - & $\begin{array}{l}(1.699710194,0, .4095616885,-1.140189766) \\
(1.025062190,1.341247016, .3341720874,-1.241803182)\end{array}$ \\
\hline- & $\begin{array}{l}\text { Social } \\
\text { Optimum }\end{array}$ & - & $n^{*}=4.4273139, \tau^{*}=.296681, U_{\max }=-1.066475$ \\
\hline 0 & $\begin{array}{l}\text { Fixed } \\
\text { Convention }\end{array}$ & 573.2 & $(1.6958508998,0,0.409831247,-1.140547454)$ \\
\hline 0 & $\begin{array}{l}\text { Fixed } \\
\text { Convention }\end{array}$ & 0 & $\begin{array}{l}(1.5989049725,0,0.41682122123,-1.1501342368) \\
(.8658794251,1.477940857, .3265849827,-1.270158580)\end{array}$ \\
\hline 0 & $\begin{array}{l}\text { Learned } \\
\text { Convention }\end{array}$ & -0.121472602158 & $(1.59835683672,0,0.4168619874,-1.1501919166)$ \\
\hline 0.035 & $\begin{array}{l}\text { Learned } \\
\text { Convention }\end{array}$ & -0.0884944056 & $(1.4123165415,0,0.39660878-1.1724263009)$ \\
\hline \hline
\end{tabular}

Table 3: Steady-state local learning and subgame perfect gift equilibria for the economy with $\delta_{0}=0.01$

\begin{tabular}{|c|c|c|l||}
\hline \hline$\tau$ & $\begin{array}{l}\text { Equilibrium } \\
\text { Concept }\end{array}$ & $\sigma^{\prime *}$ & $\left(n^{*}, s^{*}, a^{*}, U_{\max }\right)$ \\
\hline- & $\begin{array}{l}\text { Social } \\
\text { Optimum }\end{array}$ & - & $n^{*}=2.229280716, \tau^{*}=.2964089, U_{\max }=-.8944282$ \\
\hline 0 & $\begin{array}{l}\text { Learned } \\
\text { Convention }\end{array}$ & 0.0140687 & $(4.260833,0,0.0398846038,-1.1509245896)$ \\
\hline 0.035 & $\begin{array}{l}\text { Learned } \\
\text { Convention }\end{array}$ & 0.036904528 & $(3.6475198,0,0.00802,-1.1506664)$ \\
\hline \hline
\end{tabular}

Note that in both economies, a PAYG social security reduces the local subgame perfect 


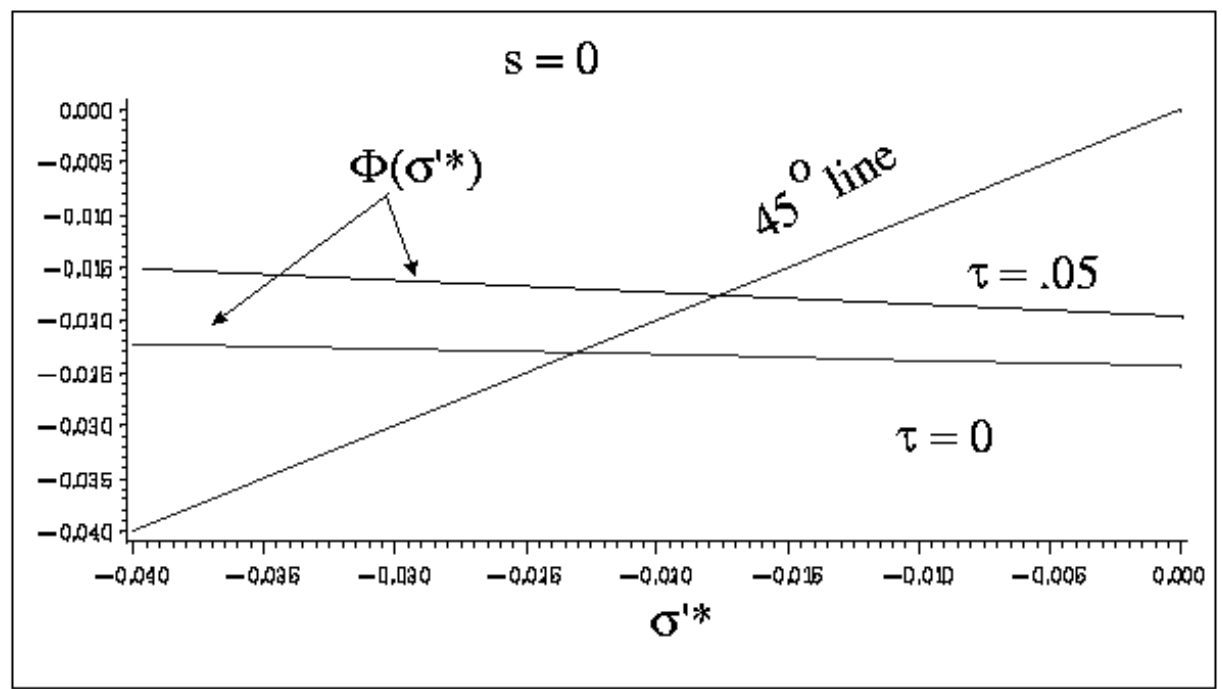

(a)

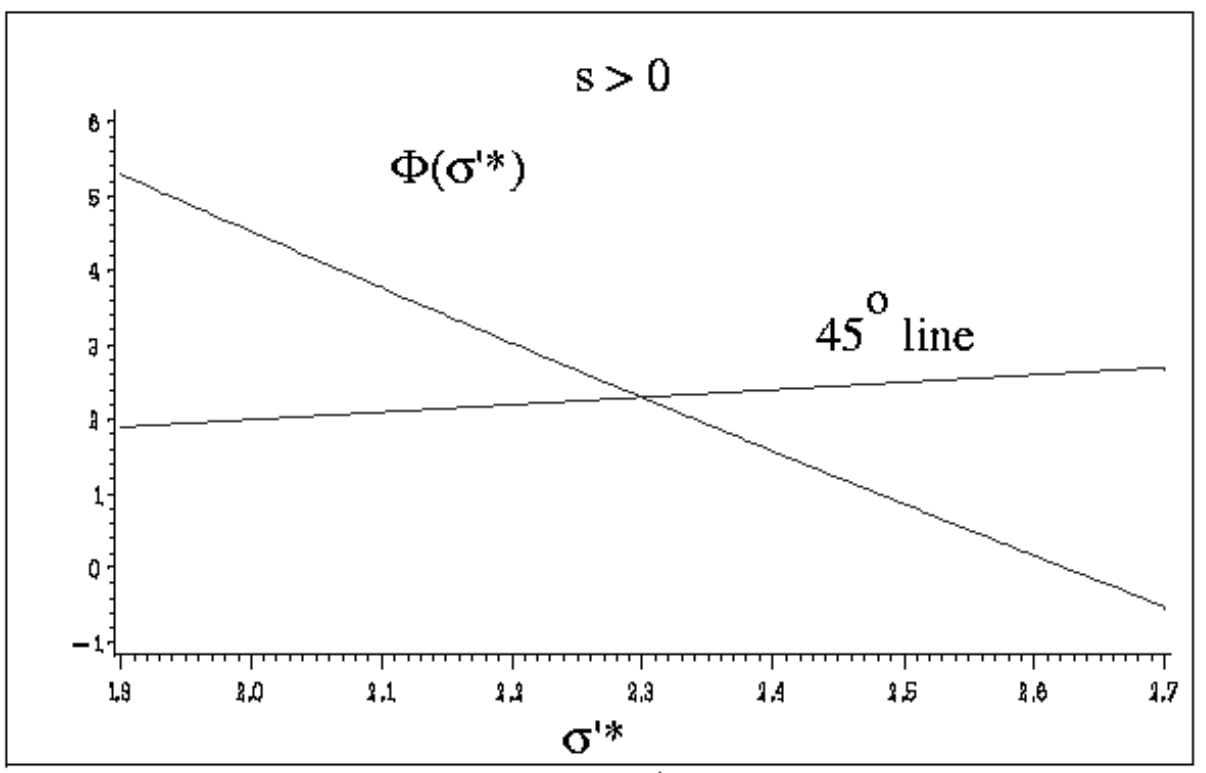

(b)

Figure 3: Phase diagram of learning equilibrium for numerical CEM economy 
equilibrium fertility level. The main distinguishing features of these two economies are that for the economy of the first table, the socially optimal fertility rate is above the local subgame perfect equilibrium level of fertility and introduction of a social security reduces the steady-state welfare level of a representative agent. For the economy of the second table, the socially optimal fertility level is below the local subgame perfect equilibrium fertility level, and introduction of a social security program improves the steady-state welfare level of a representative agent. These qualitative properties are insensitive to small changes to the parameter values. Furthermore, neither economies produced convergent convention sequences for equilibrium of either type (i.e., $s=0$, or $s>0$ ) when I tried social security tax rate close to the rate implied by the social optimal solution.

\section{Properties of Gift Equilibrium}

In this section I study the properties of steady-state local learning equilibria for which the associated $\sigma^{*}>-1$. These results are also true, in particular, for any local subgame perfect gift equilibria for which the associated $\sigma^{*}>-1$ (this is true for instance, for the CEM economy in our numerical example above). The following proposition shows that the equilibrium reaction of children to parents' higher savings is to reduce old-age support to their parents.

Proposition 2 Let $\mathrm{v}\left(\right.$.) be twice continuously differentiable with $v^{\prime \prime}(c)<0 \forall c>0$, then for all $(n, s)$ that lead to positive consumptions in each period, equation (13) has a continuously differentiable solution $a(n, s)$ and $\partial a(n, s) / \partial s<0$.

Proof. Assume that $\tau=0$. Substituting $s+\theta n=\sigma(a)$ from equation (16) in equation (12), we have an implicit function $\Phi(n, s, a)=0$ for which

$$
\frac{\partial \Phi(.)}{\partial a}=-w\left[\mathrm{v}^{\prime \prime}\left(c_{1}^{*}\right)\left(1+\sigma^{*}\right)+\mathrm{v}^{\prime \prime}\left(c_{2}^{*}\right) \delta(n) n^{2} / \alpha\right]>0
$$

Hence the first part follows from the implicit function theorem. Using the implicit function theorem again, we have

$$
\frac{\partial a(n, s)}{\partial s}=-\frac{(1+r) \mathrm{v}^{\prime \prime}\left(c_{2}^{*}\right) \delta(n) n / \alpha}{w\left[\mathrm{v}^{\prime \prime}\left(c_{1}^{*}\right)\left(1+\sigma^{\prime *}\right)+\mathrm{v}^{\prime \prime}\left(c_{2}^{*}\right) \delta(n) n^{2} / \alpha\right]}<0
$$

Q.E.D. 
While the effect of a parent's savings on the rate of transfers from children is negative, it's effect on the number of children is ambiguous. To see this, denote by $\phi(n) \equiv \delta(n) . n / \alpha$ and assume that $\phi(n)$ is an increasing function of $n$. Proceeding in the same manner as in the proof of the previous proposition, it follows that

$$
\frac{\partial a(., .)}{\partial n}=-\frac{\phi^{\prime}(n) \mathrm{v}^{\prime}\left(c_{2}^{*}\right)+\left[\phi(n) a(., .) w \mathrm{v}^{\prime \prime}\left(c_{2}^{*}\right)\right]}{\left[w \mathrm{v}^{\prime \prime}\left(c_{1}^{*}\right)\left(1+\sigma^{\prime *}\right)+\phi(n) w n \mathrm{v}^{\prime \prime}\left(c_{2}^{*}\right)\right]}
$$

Note that both the bracketed terms in the above are negative and the first term of the numerator are positive. Thus the sign of the right hand side of the above partial derivative will depend on the relative magnitudes of the bracketed terms and the first term on the numerator. In the numerical example that I considered earlier, the right hand side is unambiguously negative for all the parameter values that I considered. That means, if parents have more children, they would receive less gifts from each child. The total gift, however, could be higher.

The following proposition finds condition under which a local learning equilibrium is also a open-loop gift equilibrium in the steady-state.

Proposition 3 A stationary local gift equilibrium with common convention $\sigma^{* *}=\infty$ is also a steady-state open-loop gift equilibrium

Proof. Notice above that if $\sigma^{\prime *}=\infty$, then both $a_{1}(n, s)$ and $a_{2}(n, s)$ are zero for equilibrium reaction function $a($.$) , and thus it follows from equations (13)-(12) and equation (??)$ that the equilibrium conditions for the steady-state local learning equilibrium is the same as the conditions for steady-state open-loop gift equilibrium.

\section{Q.E.D.}

Although, a threat to parents by the children of the type $\sigma^{\prime *}=\infty$ leads to open-loop Nash equilibrium but it is incredible since it sounds like:

"if his parents choose levels of fertility and saving different from that are prescribed by the open loop Nash-equilibrium level $n^{*}, s^{*}$ and thus induce him to transfer more (resp. less) amount than that is prescribed by open-loop Nash equilibrium, he will consume nothing (resp. consume everything that he has, and if necessary he will borrow against his children) during his adult age." 
A feasible steady-state allocation is said to be Pareto Optimal if there does not exist another feasible steady-state allocation that gives higher utility to a representative agent. 1

Proposition 4 Consider an economy that has a stationary local gift equilibrium with common convention $\sigma^{\prime *}$ as $\left(s^{*}, n^{*}, a^{*}(.,).\right)$ with $s^{*}=0$ and no bequest constraint (13) holds as a strict inequality, and suppose further that the equilibrium satisfies:

$$
\beta-\left(\frac{\gamma\left(n^{*}\right)}{n^{*}}\right) \cdot\left(\frac{v^{\prime}\left(c_{1}^{*}\right)}{v^{\prime}\left(c_{2}^{*}\right)}\right) \equiv \mu>0 \text { and } \delta\left(n^{*}\right)<\mu
$$

then all agents can be made better-off with a suitably designed pay-as-you-go social security program. Hence such an equilibrium is not Pareto optimal.

Proof. Consider a pay-as-you-go social security program which marginally taxes all adult agents and redistributes the revenues equally among their old parents. Suppose for the moment that agents do not change their fertility and savings decisions in response to introduction of such a social security program. The utility gains of a representative agent is $n^{*} \beta \mathrm{v}^{\prime}\left(c_{2}^{*}\right)$ from the increased consumption in the old-age. The utility loss is given by $\alpha \mathrm{v}^{\prime}\left(c_{1}^{*}\right)+\gamma(n) \mathrm{v}^{\prime}\left(c_{1}^{*}\right)$, where the first term corresponds to welfare loss due to fall in own adult-age consumption and the second term corresponds to the welfare loss due to reduction in children's adult-age consumption. Thus the net gain is

$$
\begin{aligned}
\triangle U & =n^{*} \beta \mathrm{v}^{\prime}\left(c_{2}^{*}\right)-\alpha \mathrm{v}^{\prime}\left(c_{1}^{*}\right)-\gamma\left(n^{*}\right) \mathrm{v}^{\prime}\left(c_{1}^{*}\right) \\
& =n^{*} \beta \mathrm{v}^{\prime}\left(c_{2}^{*}\right)-\delta\left(n^{*}\right) n^{*} \mathrm{v}^{\prime}\left(c_{2}^{*}\right)-\gamma\left(n^{*}\right) \mathrm{v}^{\prime}\left(c_{1}^{*}\right) \\
& =n^{*}\left(\beta \mathrm{v}^{\prime}\left(c_{2}^{*}\right)-\gamma\left(n^{*}\right) \mathrm{v}^{\prime}\left(c_{1}^{*}\right)\right)-\delta\left(n^{*}\right) n^{*} \mathrm{v}^{\prime}\left(c_{2}^{*}\right) \\
& >0
\end{aligned}
$$

In deriving the above I have used equation (13). The fertility will also respond to the social security program.. If the fertility rate without a social security program is above the social optimal rate ( in our numerical simulation I found this to be the case when an economy satisfies condition (19), for instance, the economy in table [1), introduction of a social security program with a small tax rate $\tau$ will lead to a higher utility level of the

\footnotetext{
${ }^{4}$ This is a modified version of Pareto Optimality, modified to take into account the problem of comparing non-existing individuals' utililities under two different feasible steady-state allocations. See Raut [1990] for a discussion of this problem and the related literature on this issue.
} 
representative agent (see again the numerical example in tableß3). If the initial fertility rate of the subgame perfect equilibrium without social security is, however, lower than the socially optimal fertility level, one needs to integrate a social security program with an appropriate population policy so that fertility rate does not fall because of social security. With this integration of policies, a social security program can lead to a higher utility level of a representative agent in the steady-state.

\section{Q.E.D.}

The implication of the above results for social security program is that when fertility is endogenous, introduction of a social security program may improve welfare level of a representative agent. But unlike in the case of exogenous fertility, the social security by itself would not produce the social optimal welfare level for a representative agent. The social security program needs be complemented by an appropriate population policy to attain social optimal.

\section{Conclusion}

In this paper I have considered an OLG model of endogenous fertility, savings and intergenerational transfers. I have argued that the commonly used open-loop Nash equilibrium does not fully capture the individual incentives that agents have in making these decisions in an OLG economy. It is more appropriate to use the notion of subgame perfect equilibrium. There are generally multiple subgame perfect equilibria and it is, in general, difficult to compute a subgame perfect equilibrium. I have introduced a unifying notion of equilibrium in which behaviors are guided by best responses given a fixed convention and bounded rational expectations about other agents' behaviors. This equilibrium notion includes both the notions of subgame perfect equilibrium and the open loop Nash equilibrium as special cases. I have provided a learning mechanism specifying how agents learn about the common convention by observing their parent generation's choices. This generates an evolutionary process for convention. I have shown that when this evolutionary process converges, the resulting learned convention produces a subgame perfect equilibrium. This provides a rationale for equilibrium selection and a method to compute a subgame perfect equilibrium 
locally around a steady-state. I have used this method to compute a local subgame perfect equilibrium numerically using the Maple software and my own $\mathrm{C}++$ codes.

Based on analytical and numerical results, I have shown that a PAYG social security program improves the steady-state welfare level of a representative agent when the fertility level without social security in the subgame perfect equilibrium is higher than the socially optimal level. When the fertility level without social security in the subgame perfect equilibrium is lower than the socially optimal level, a PAYG social security program lowers the welfare level. Furthermore, I have shown that a PAYG social security program always reduced the fertility level and the level of voluntary within family old-age support. The reduction in old-age support is, however, less than a dollar for a dollar increase in social security benefits. 


\section{References}

Barro, R. [1974], "Are Government Bonds Net Wealth," Journal of Political Economics, vol. 82(6):1095-1117.

Becker, G.S. [1974], "A Theory of Social Interactions," Journal of Political Economics, vol 82(6):1063-1093.

Becker, G.S. and Barro, R. [1988], "A Reformulation of Economic Theory of Fertility", Quarterly Journal of Economics, vol. CIII(1):1-25.

Bernheim, B.D.; A. Shleifer, and L.H. Summers [1985], "The Strategic Bequest Motive," Journal of Political Economics, vol. 93(6):1045-1076.

Browning, E.K. [1975], "Why the social insurance budget is too large in a democracy", Economic Inquiry, vol. 13: 373-388.

Diamond, P. A. [1977] " A framework for social security analysis," Journal of Public Economics, vol. 8:275-298.

Diamond, P.A. and J. A. Mirrlees [1978], "A model of social insurance with variable retirement," Journal of Public Economics, vol. 10:295-336.

Fudenberg, D. and D. Levine [1998], "Learning and Evolution: Where do we stand?," European Economic Review, vol.42, n3-5: 631-39

Hansson, I and C. Stuart [1989], "Social Security as Trade among Living Generations", American Economic Review, vol.79(5).

Kohlberg, Elon [1976], "A Model of Economic Growth with altruism between generations," Journal of Economic Theory, vol.13:1-13.

Nishimura K and Zhang, J. [1992], "Pay-as-you-go Public Pensions with Endogenous Fertility," Journal of Public Economics, vol.48:239-258.

Pollak, R. [1988], "Tied Transfers and Paternalistic Preferences”, American Economic Review, vol.78(2).

Raut, L.K. [1990], "Capital Accumulation, Income Distribution and Endogenous Fertility in an Overlapping Generations General Equilibrium Model", Journal of Development Economics, vol.34(1/2): 123-150.

Raut, L.K. and L. H. Tran [2004], "Parental Human Capital Investment and Old-Age Transfers from Children: Is it a loan contract or reciprocity for Indonesian families?", Journal of Development Economics, forthcoming.

Samuelson, Paul [1958], "An Exact Consumption-Loan Model of Interest with or without the Social Contrivance of Money," Journal of Political Economics, LXVI(6).

Veall, M. R. [1986], "Public Pensions as Optimal Social Contracts" Journal of Public Economics, vol.31:237-251.

Weibull, Jorgen W. [1995], "Evolutionary Game Theory,", MIT Press, Cambridge, Massachusetts. 